\title{
Presentation of acute pulmonary edema in severe pre-eclamptic pregnant women: a case report
}

\author{
Karishma Chaudhary*, Mamta Tyagi, Smriti Gupta, Manvi Gupta, \\ Yamini Verma, Kanishka Yadav
}

Department of Obstetrics and Gynecology, Subharti Medical College, Meerut, Uttar Pradesh, India

Received: 20 July 2021

Accepted: 10 August 2021

*Correspondence:

Dr. Karishma Chaudhary,

E-mail: karishma1plus@gmail.com

Copyright: (c) the author(s), publisher and licensee Medip Academy. This is an open-access article distributed under the terms of the Creative Commons Attribution Non-Commercial License, which permits unrestricted non-commercial use, distribution, and reproduction in any medium, provided the original work is properly cited.

\begin{abstract}
Pulmonary edema refers to an excessive accumulation of fluid in the pulmonary interstitial and alveolar spaces. It may occur in low risk pregnancies but one very important predisposing factor is association with pre-eclampsia. Acute pulmonary edema during pregnancy is very rare and occurs in $0.08 \%$ pregnancies. About $3 \%$ of severe pre-eclamptic patients develop acute pulmonary edema. Several risk factors have been identified: preeclampsia or eclampsia, use of tocolytic therapy, severe infection, cardiac disease, iatrogenic fluid overload, and multiple gestations. This case examines one such presentation and reviews some of the diagnostic possibilities.
\end{abstract}

Keywords: Pregnancy, Severe pre-eclampsia, Acute pulmonary edema, Acute pulmonary edema in pre-eclampsia, Emergency cesarean section, Complications in pregnancy

\section{INTRODUCTION}

Acute pulmonary edema in pregnant women is a lifethreatening event and though an uncommon event in pregnancy $(0.08 \%)$, is associated with an increased risk of maternal and fetal morbidity and mortality. ${ }^{1}$ About $3 \%$ of severe pre-eclamptic patients develop acute pulmonary edema. Among them 30\% develop it in the antenatal period with $90 \%$ having pre-existing chronic hypertension and $70 \%$ develop it in the postnatal period. Pulmonary edema is infrequently encountered in patients with severe pre-eclampsia without associated medical, surgical or obstetric complications. In an analytical study of 37 consecutive cases by Sibai et al pulmonary edema was diagnosed in $2.9 \%$ of cases complicated by severe preeclampsia and eclampsia.

HELLP syndrome is a combination of symptoms described as hemolysis, elevated liver enzymes and low platelets, and the acronym HELLP refers to hemolysis $(\mathrm{H})$, elevated liver enzymes (EL) and low platelet count (LP). HELLP occurs in $0.5-1 \%$ of all pregnancies. ${ }^{3}$ HELLP syndrome is associated with severe clinical complications, including pulmonary edema, renal failure, disseminated intravascular coagulation (DIC), and liver infarction and liver haematoma or rupture with haematoma. ${ }^{4}$ If untreated, HELLP syndrome can lead to maternal end-organ failure and death. In this case report, we aimed to present a woman with antepartum HELLP syndrome complicated by pulmonary edema during the time of labour following severe pre-eclampsia.

\section{CASE REPORT}

A 21 years, un-booked primigravida with single intrauterine fetus with gestational age of 39 weeks presented to Triage of Swami Vivekanand Subharti University, intubated from outside hospital with blood pressure $86 / 76 \mathrm{mmHg}, \mathrm{SpO}_{2} 54 \%$ with urine showed albumin (+++) with bilateral crepts present in chest and pedal edema.

\section{On examination}

On per-abdomen examination uterus term size, fetal heart sound could not be auscultated, on per vaginum 
examination os $7 \mathrm{~cm}$ dilated with thick meconium stained liquor with presenting part vertex at station -1 .

\section{Investigations}

COVID 19 RT-PCR negative. Blood group A positive and urine albumin was +++. Hb- $12.5 \mathrm{~g} \%$, TLC- 23140, platelet count- 1.5 lakhs, PT-INR- 1.77 and APTT- 36.6.

LFT: T. bilirubin- 2.2, SGPT- 496, SGOT- 834, LDH1875. KFT: urea-56, creatinine-1.29. Echo revealed LVEF-25\% with mild MR and LV hypokinesia.

In ultrasonographic for fetal well-being examination, single intrauterine fetus with mean gestational age of 35 weeks 3 days with absent fetal heart with oligohydroamnios.

In USG whole abdomen, no free fluid seen on visualized examination at the time of scan.

A chest radiograph (Figure 1) taken at the bedside showed widespread interstitial shadowing consistent with pulmonary oedema. An echocardiogram was performed, which showed left ventricular hypertrophy, indicating that the patient had longstanding hypertension.

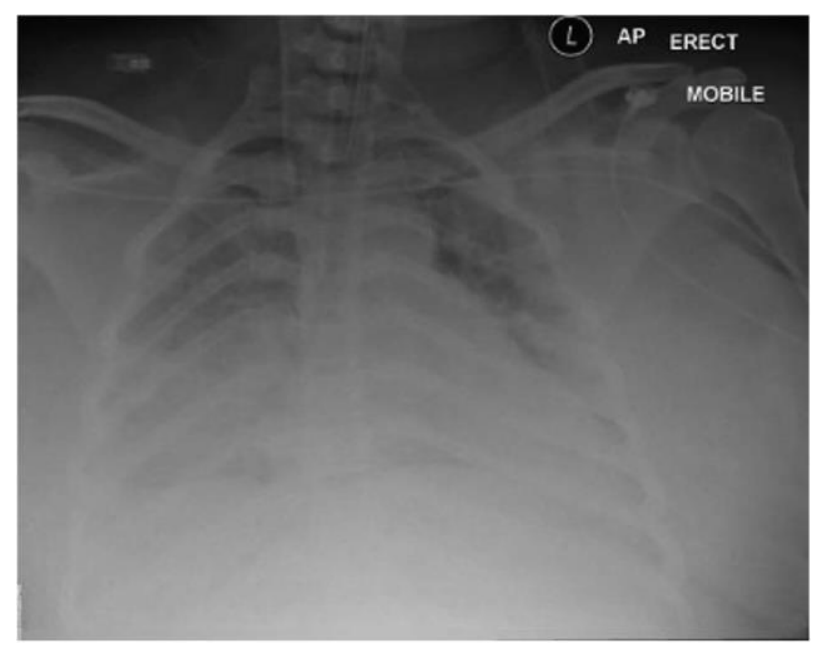

Figure 1: Mobile anteroposterior (AP) chest radiograph showing widespread interstitial shadowing consistent with pulmonary oedema.

\section{Diagnosis- HELLP syndrome with acute pulmonary edema}

Patient's condition was deteriorating clinically, shifted to ICU after taking high risk consent, anesthesia reference was done in view of falling $\mathrm{SpO}_{2}$ and patient was put on midazolam infusion, decided for LSCS + elective postoperative ventilatory support.

Emergency LSCS was done i/v/o CPD with severe preeclampsia with pulmonary oedema under general anesthesia with high risk consent. A dead baby boy of weight $3.5 \mathrm{~kg}$ with Apgar score 0, 0 delivered. Postoperatively she was put on ventilator support and slowly weaned. As tachypnoea was persisting Chest X-ray was done which showed features of consolidation. Patient was extubated on post-op day 2 but had to be re-intubated after 2 days i/v/o acute respiratory distress syndrome with falling $\mathrm{SpO}_{2}$. $\mathrm{Tb}$ and chest, medicine and ophthalmology reference was done and advice followed. patient was taken on higher antibiotics, tablet tamiflu, corticosteroids and 6 fresh frozen plasma and 1-unit PRBC were transfused. It was managed with antibiotics. Patient got better and was discharged on day 17.

\section{DISCUSSION}

HELLP syndrome is a poorly understood pregnancyrelated condition with a rapid onset and is typically seen in patients with severe pre-eclampsia, although it can occur in the absence of pre-eclampsia in $10 \%$ of the cases. HELLP is a multisystem disease, resulting in generalized vasospasm, microthrombi formation and coagulation defects. The syndrome seems to be the final manifestation of insult that leads to microvascular endothelial damage and intravascular platelet aggregation. ${ }^{5}$

Acute pulmonary oedema may be caused by a variety of perturbations of any one of the key determinants of cardiovascular function and fluid flow into the pulmonary interstitium. The causes of pulmonary edema are often multifactorial. According to the Starling equation, any factor that results in a reduction in colloid osmotic pressure (or in the colloid osmotic pressure/pulmonary capillary wedge pressure gradient), an increase in capillary permeability, or an increase in intravascular hydrostatic pressure will lead to extravasation of fluid from the vasculature and predispose to the development of pulmonary oedema. ${ }^{6}$

Our patient satisfied all the criteria of HELLP syndrome. She had hemolysis as evidenced by anemia, raised bilirubin and $\mathrm{LDH}$, elevated liver enzymes, and low platelets. Thus, our patient was adequately evaluated, diagnosed and received intensive care management, which led to a favorable outcome. Our case highlights the importance of proper preoperative evaluation of preeclampsia patients to the diagnosis of HELLP syndrome.

\section{CONCLUSION}

Acute pulmonary oedema is an indicator of significant morbidity and may lead to mortality in pregnant women. It is paramount to identify the at-risk patient, recognise signs of critical illness and manage these women with a skilled multidisciplinary team. Risk reduction strategies should include an emphasis on the importance of fluid balance and recording regular clinical observations.

Funding: No funding sources

Conflict of interest: None declared

Ethical approval: Not approved 


\section{REFERENCES}

1. Sciscione AC, Ivester T, Largoza M, Manley J, Shlossman P, Colmorgen GH. Acute pulmonary edema in pregnancy. Obstet Gynecol. 2003;101(3):511-5.

2. Sibai BM, Mabie BC, Harvey CJ, Gonzalez AR. Pulmonary edema in severe preeclampsia-eclampsia: analysis of thirty-seven consecutive cases. Am J Obstet Gynecol. 1987;156(5):1174-9.

3. Baxter JK, Weinstein L. HELLP syndrome: the state of the art. Obstet Gynecol Surv. 2004;59(12):838-45.
4. Dusse LM, Alpoim PN, Silva JT, Rios DR, Brandão AH, Cabral AC. Revisiting HELLP syndrome. Clin Chim Acta. 2015;451:117-20.

5. Genest G, Spitzer KA, Laskin CA. Maternal and Fetal Outcomes in a Cohort of Patients Exposed to Tumor Necrosis Factor Inhibitors throughout Pregnancy. J Rheumatol. 2018;45(8):1109-15.

6. Berne R, Levy M. Cardiovascular Physiology. 1st ed. St. Louis: Mosby Year Book; 1992.

Cite this article as: Chaudhary K, Tyagi M, Gupta S, Gupta M, Verma Y, Yadav K. Presentation of acute pulmonary edema in severe pre-eclamptic pregnant women: a case report. Int J Reprod Contracept Obstet Gynecol 2021;10:3620-2. 